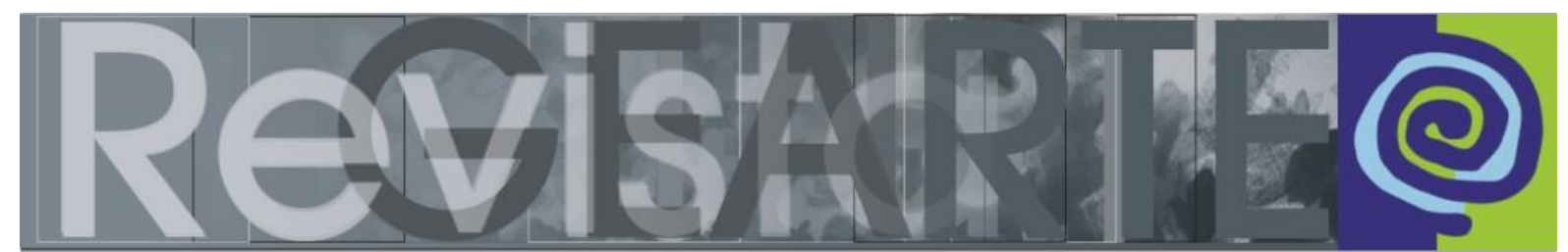

ISSN 2357-9854 | e-ISSN 2596-3198 (online)

\title{
Uma estética da violência presente no cinema brasileiro e o apagamento de mulheres negras nas produções audiovisuais
}

\author{
Bárbara Cezano Rody \\ (Universidade Federal de Pelotas — UFPel, Pelotas/RS, Brasil) \\ Larissa Patron Chaves \\ (Universidade Federal de Pelotas — UFPel, Pelotas/RS, Brasil)
}

RESUMO - Uma estética da violência presente no cinema brasileiro e o apagamento de mulheres negras nas produções audiovisuais - Pensar na história do cinema brasileiro e mulheres negras em conjunto ainda soa como um par muito distante, devido ao apagamento dessas produtoras na história do cinema de nosso país. Este artigo foi iniciado a partir das inquietações que surgiram ao pesquisar notícias veiculadas pela EBC (Empresa Brasileira de Comunicação) a respeito da participação de mulheres como cineastas e da não visibilidade da participação de cineastas negras nesse cenário. Essas mulheres não existiam nesse cenário ou seria essa mais uma consequência da invisibilidade de nossxs corpxs?

PALAVRAS-CHAVE

Mulheres negras. Cinema. Visibilidade. Cineastas negras. Estética.

ABSTRACT - An aesthetic of violence present in Brazilian cinema and the erasure of black women in audiovisual productions - To think about Brazilian cinema history and black women as one, still sounds like a very distant thing, due to the erasure of these female film productor in our country's history. This article was initiated from the concerns that have arisen when EBC's (Empresa Brasileira de Comunicação) aired news about women participation as filmmakers and also about the lack of visibility of black female filmmakers participation in this scenario. Didn't these women actually exist in this scenario, or is this another consequence of our bodies invisibility?

KEYWORDS

Black women. Cinema. Visibility. Black filmmakers. Aesthetic.

RESUMEN - Una estética de la violencia presente en el cine brasileño y el apagón de las mujeres negras en las producciones audiovisuales - Pensar en la historia del cine brasileño y las mujeres negras juntas todavía suena como una pareja muy distante, debido a la eliminación de estas productoras en la historia del cine en nuestro país. Este artículo se inició a partir de las preocupaciones que surgieron al investigar noticias publicadas por EBC (Empresa Brasileira de Comunicação) con respecto a la participación de mujeres como cineastas y la no visibilidad de la participación de cineastas negras en este escenario. ¿No existían estas mujeres en este escenario o era otra consecuencia de la invisibilidad de nuestros cuerpos?

\section{PALABRAS CLAVE}

Mujeres negras. Cine. Visibilidad. Cineastas negras. Estética. 


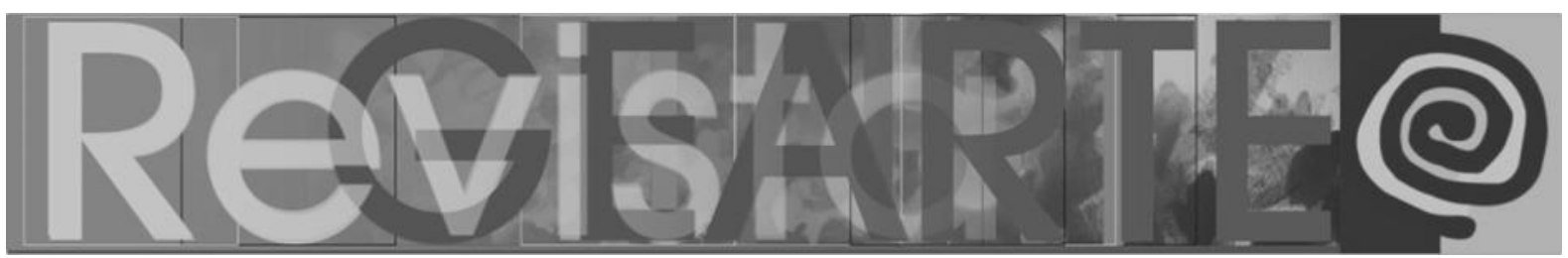

O site da Agência Brasil, difusora de notícias brasileiras da empresa pública EBC (Empresa Brasileira de Comunicação), divulgou em 2014, a pesquisa desenvolvida pela Universidade Estadual do Rio de Janeiro (UERJ) que analisou alguns filmes nacionais de 2002 a 2012 e verificou que as mulheres negras apareceram em menos de dois a cada dez longas-metragens. Segundo a escritora da matéria, Isabel Vieira", "atrizes pretas e pardas representaram $4,4 \%$ do elenco principal de filmes nacionais. Neste período, nenhum dos mais de 218 filmes nacionais de maior bilheteria teve uma mulher negra na direção ou como roteirista." Sendo o Brasil, um país em que $53 \%$ da sua população se declara preta ou parda, podemos perceber que o cinema nacional não reflete o perfil diverso de nosso território que se centra na afrodescendência tanto em traços raciais quanto culturais.

A autora da pesquisa, Marcia Rangel, confirma essa observação na entrevista que deu para a matéria, pelo o que ela mesma descreve como "total exclusão" de mulheres negras em cargos técnicos. Além de serem poucas as representações no elenco, em sua maioria são estereotipadas, buscando a criminalidade e violência como estética de representatividade desses corpos.

De acordo com a pesquisa, as mulheres ocupam $14 \%$ dos cargos de direção e $26 \%$ nos cargos de roteiristas dentre os filmes mais vistos, sendo que durante o período de 10 anos, recorte temporal feito pelas pesquisadoras, não havia diretoras e roteiristas negras entre os filmes selecionados para a pesquisa.

Essa matéria despertou meu interesse particular por querer entender onde estão as produtoras negras do audiovisual brasileiro. Essas mulheres não existiam nesse cenário ou seria essa mais uma consequência da invisibilidade de nossxs corpxs? Seria o alto custo de investimento para produzir um longa-metragem um dos empecilhos para as produtoras negras? Ou ainda, se elas existem e produzem.

1 Rio de Janeiro, 06 de julho de 2014. Seção Geral. Disponível em: <http://agenciabrasil.ebc.com.br/cultura/noticia/2014-07/pesquisa-revela-que-mulheres-negrasestao-fora-do-cinema-nacional> Acesso em: 31 ago. 2019. 


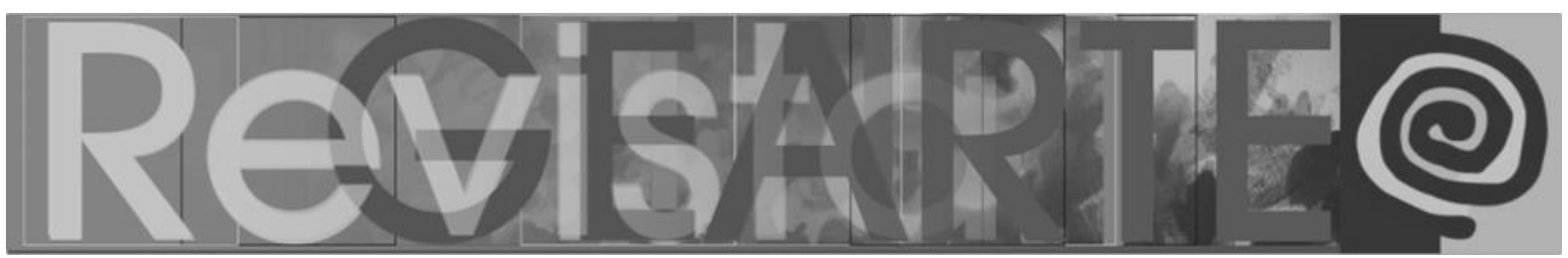

A questão da invisibilidade estaria atrelada a quem seleciona e olha essas produções, ou seja, as curadorias?

Através da investigação feita principalmente em algumas matérias publicadas no site Agência Brasil2, como também pela própria história de nosso cinema nacional, olho atentamente para a participação da mulher negra no cinema, sobretudo de sua importante participação na construção do Cinema Negro Brasileiro.

Retorno a pesquisa comentada acima e paro para pensar sobre os disparadores que levaram à estereotipação das mulheres negras através da estética da violência.

A história do cinema brasileiro se entrelaça à história da política nacional, os primeiros investimentos em distribuição e comercialização de filmes por parte da União foram concretizados na forma da Embrafilme - Empresa Brasileira de Filmes S.A - em 1969. A princípio a Embrafilme surge como um apêndice do Instituto Nacional de Cinema (INC), criado em 1966, mas sua força se sobressai ao INC que chega a ser extinto em 1975.

Tendo cerca de $70 \%$ de suas ações de posse da União e os outros $30 \%$ divididos entre acionistas, a Embrafilme era uma empresa cujo os principais objetivos eram a difusão do filme brasileiro em território nacional e no exterior, posteriormente também exerceu atividades comerciais e industriais no mercado cinematográfico ${ }^{3}$.

Dentre suas responsabilidades estava o Programa de Financiamento de Filmes Brasileiros de Longa-metragem, viabilizando recursos para algumas

2 É uma agência de notícias públicas, gerida pela Empresa Brasil de Comunicação (EBC), comandada pelo Poder Executivo Brasileiro.

3 As informações apresentadas aqui foram retiradas do livro Embrafilme e o cinema brasileiro, de 2007 e compõe a publicação de e-books "Coleção cadernos de pesquisa", no site do Centro de Cultura de São Paulo. 


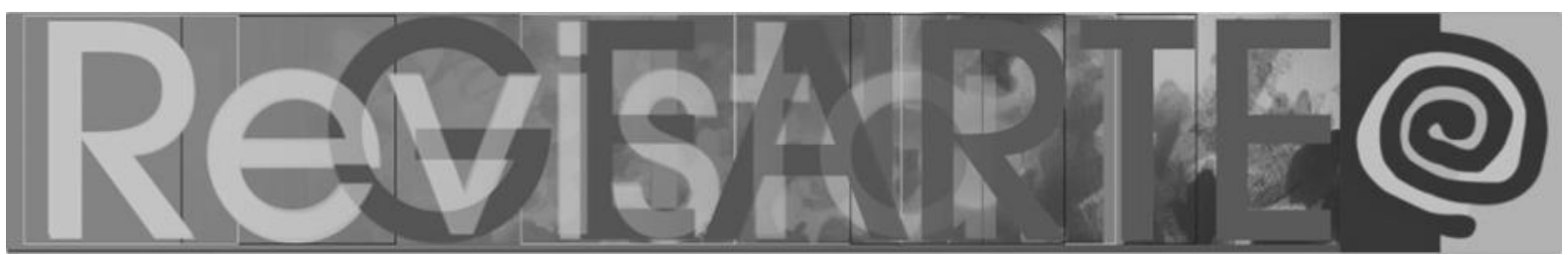

produções audiovisuais no Brasil. E como parte do compromisso da empresa também se responsabilizavam enquanto distribuidora. Tendo em 1973, São Bernardo, de Leon Hirszman, como o primeiro filme a ganhar mercado a partir dos investimentos da Embrafilme, se tornando um clássico do Cinema Novo.

Aliás, o desenvolvimento e produção do Cinema Novo tem a Embrafilme como elemento importante para sua concretização e promoção, sendo seus principais nomes: Cacá Diegues, Nelson Pereira dos Santos, Gustavo Dahl, Glauber Rocha e Helena Solberg ${ }^{4}$, também conhecida por ser a única mulher a participar desta corrente cinematográfica.

Para projetar questões sobre a participação das cineastas negras na história do Cinema Negro Brasileiro, é preciso retomar o começo. Proponho essa retomada pois o início do Cinema Negro tem como berço o então Cinema Novo.

\section{Mas o que seria o Cinema Novo?}

Sem querer me prender a uma detalhada retrospectiva do Cinema Novo, mas voltemos a 1965, um ano após o Golpe Militar Brasileiro. O cineasta Glauber Rocha, que ficará conhecido na história por ser o mais importante expoente do movimento, participa da Resenha do Cinema Latino-Americano, em Gênova, evento patrocinado pela Columnum, que ocorreu durante o Congresso do Terceiro

4 Cacá Diegues: nasceu em Maceió, Alagoas, em 19 de maio de 1940. Entre suas obras estão: Cinco Vezes Favela (1962), Xica da Silva (1976) e Deus é Brasileiro (2002). Conheça mais sobre esse artista através da fonte: http://www.carlosdiegues.com.br/avida_biografia.html; Nelson Pereira dos Santos: nasceu em São Paulo, 1928 e faleceu no Rio de Janeiro, em 2018. Entre suas obras estão: Rio, 40 Graus (1955) e Memórias do Cárcere (1984) e também atuo na televisão. Conheça mais sobre esse artista através da fonte: http://enciclopedia.itaucultural.org.br/pessoa370579/nelson-pereira-dossantos; Gustavo Dahl: nasceu em Buenos Aires, Argentina, 1938 e faleceu em Trancoso, Brasil, (2011).Entre suas obras estão: Dança Macabra (1962) e Tensão no Rio (1984). Conheça mais sobre esse artista através da fonte: http://enciclopedia.itaucultural.org.br/pessoa434041/gustavo-dahl; Glauber Rocha: nasceu em Vitória da Conquista, Bahia, 1939 e faleceu no Rio de Janeiro, 1981. Entre suas obras estão: Barravento e Terra em Transe, ambos finalizados em 1967. Conheça mais sobre esse artista através da fonte: https:/enciclopedia.itaucultural.org.br/pessoa10814/glauber-rocha; Helena Solberg: nasceu no Rio de Janeiro, 17 de junho de 1938. Entre suas obras estão: A entrevista (1966) e Carmen Miranda: banana is my business (1995). Conheça mais sobre esse artista através da fonte:https://www.mulheresdocinemabrasileiro.com.br/site/entrevistas_depoimentos/visualiza/193/Hel ena-Solberg 


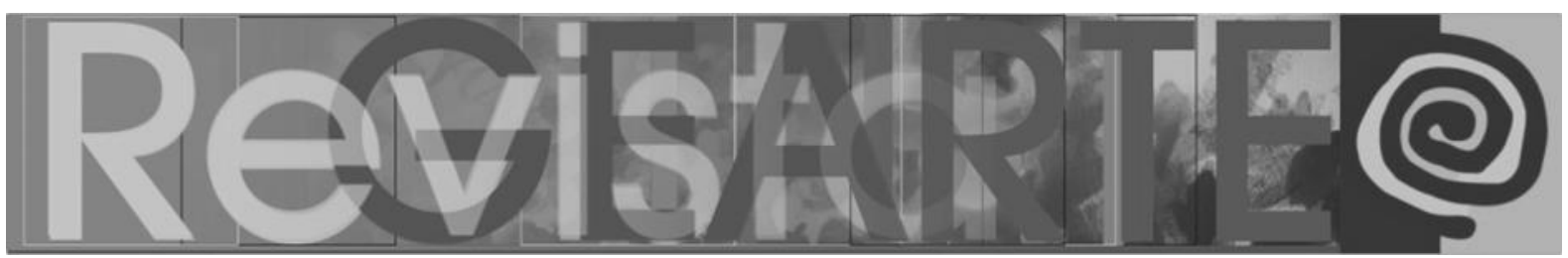

Mundo e Comunidade Mundial. Durante uma mesa-redonda, cujo tema era Cinema Novo e Cinema Mundial, o cineasta baiano apresentou a tese "Eztetyka da fome", posteriormente publicada na Revista Civilização Brasileira:

A fome latina, por isto, não é somente um sistema alarmante: é o nervo da sua própria sociedade. Aí que reside a trágica originalidade do Cinema Novo diante do cinema mundial: nossa originalidade é nossa fome e nossa maior miséria é que esta fome, sendo sentida, não é compreendida. (ROCHA, 1965).

Essa fome era retratada pelo miserabilismo e essa miserabilidade estampada era apresentada como possibilidade de oposição à tendência do digestivo, aquilo que aos olhos era mais bem aceito. Em sua maioria, filmes que retratam uma vida luxuosa, construindo uma felicidade em torno dos bens materiais, também conhecidos como filme de gente rica ${ }^{5}$, de objetivos puramente industriais, segundo palavras de Glauber Rocha (1965), que ressaltou que o Cinema Novo tem um compromisso com a verdade, com a realidade e a realidade brasileira (e da América Latina) seria a miserabilidade.

Contudo, pouco compreendido pelos brasileiros que têm vergonha dessa miséria que os cerca, e os estrangeiros que a veem de forma exotizada, o miserabilismo acaba sendo pouco discutido enquanto problema político. E para o cineasta cinemanovista, a única forma de a fome ser evidenciada de fato seria através da violência.

Do Cinema Novo: uma estética da violência antes de ser primitiva é revolucionária, eis o ponto inicial para que o colonizador compreenda a existência do colonizado: somente conscientizada sua possibilidade única, a violência, o colonizador pode compreender, pelo o horror, a força da cultura que ele explora. Enquanto não ergue as armas, o colonizado é um escravo: foi preciso um primeiro policial morto para que o francês percebesse um argelino. (ROCHA, 1965).

De fato, o movimento do Cinema Novo, e particularmente a postura de Glauber Rocha durante o Congresso Mundial na Europa, questionando a partir

5 Estética predominante das produções da Companhia Cinematográfica Vera Cruz.

RODY, Bárbara Cezano; CHAVES, Larissa Patron. Uma estética da violência presente 


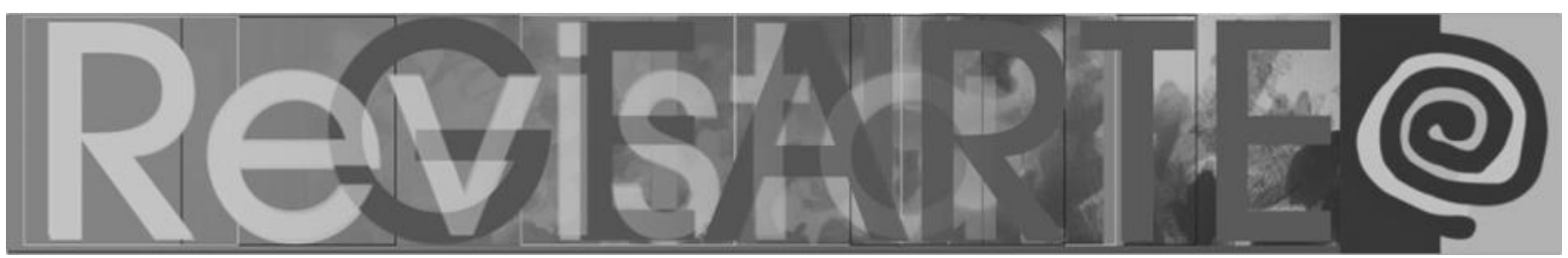

desse texto a validade da supremacia do olhar europeu sobre o terceiro mundo, são de grande importância para re-mapearmos a história de nosso cinema nacional.

Para historiadores como Anderson Neves, apesar de sua notabilidade, o Cinema Novo, em termos estéticos, especificamente em algumas obras de Glauber Rocha, ainda reproduzia padrões estéticos da grande indústria internacional. Isso é notado nos filmes $O$ dragão da maldade contra o santo guerreiro (1969) e Deus e o diabo na terra do sol (1964), que assim como o filme de Lima Barreto O Cangaceiro (1953), muito criticado na época pelos cinemanovistas, ainda se apoiavam muito na estética do gênero western.

Esse é um ponto de análise que para os entusiastas desse gênero brasileiro, também conhecido como vanguarda de resistência ao imperialismo da época, pode parecer pouco relevante.

Figura 1 - Cartaz do filme 01: Deus e o Diabo na terra do sol, de Glauber Rocha (1964)

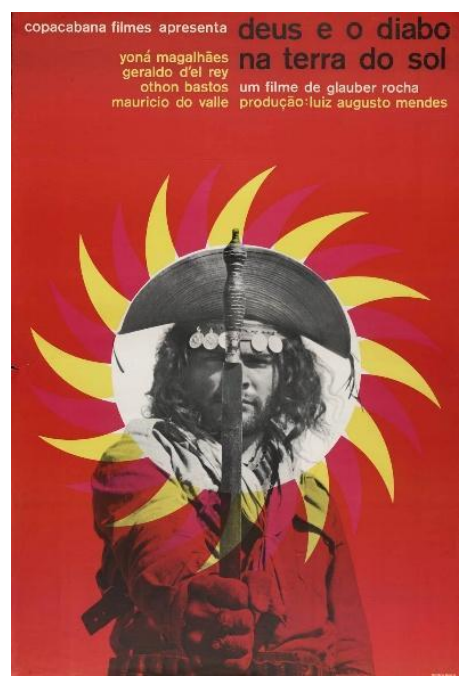

Fonte: <http://enciclopedia.itaucultural.org.br/obra70172/deus-e-o-diabo-na-terra-do-sol>. 


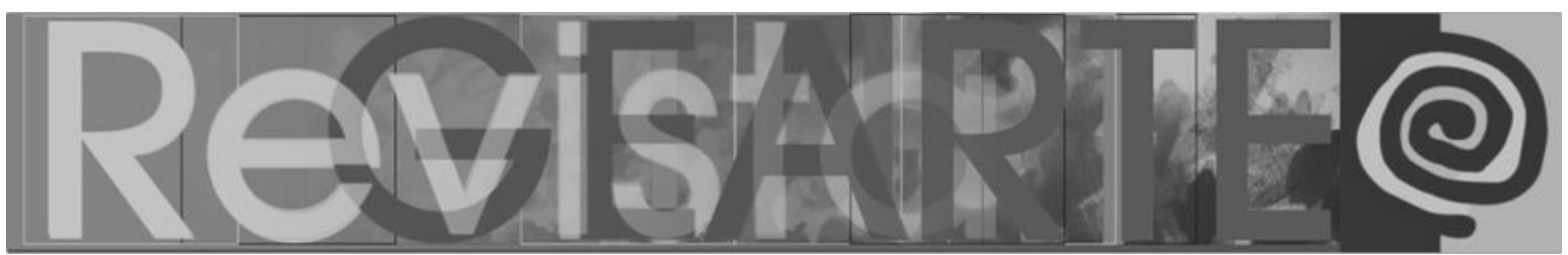

Figura 2 - Cartaz do filme 02: O dragão da maldade contra o santo guerreiro, de Glauber Rocha (1969)

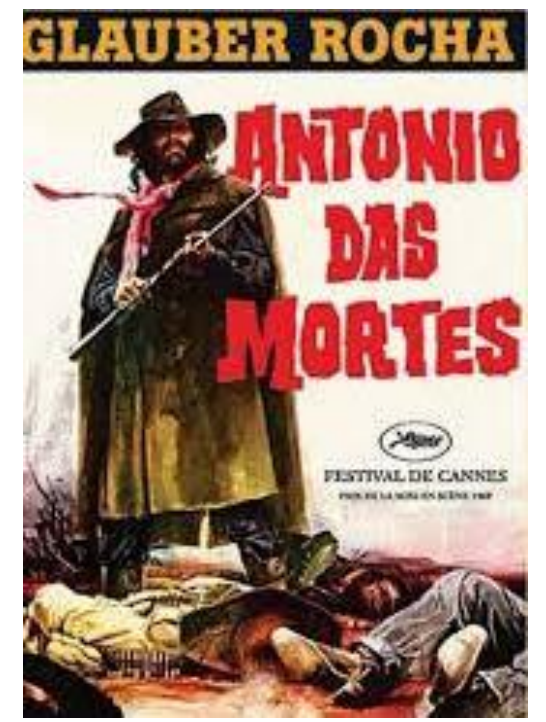

Fonte: https://pt.wikipedia.org/wiki/O_Drag\%C3\%A3o_da_Maldade_contra_o_Santo_Guerreir o\#/media/Ficheiro:O_Drag\%C3\%A3o_da_Maldade_contra_o_Santo_Guerreiro.jpg.

Figura 3 - Cartaz do filme 03: O Cangaceiro,de Lima Barreto (1953)

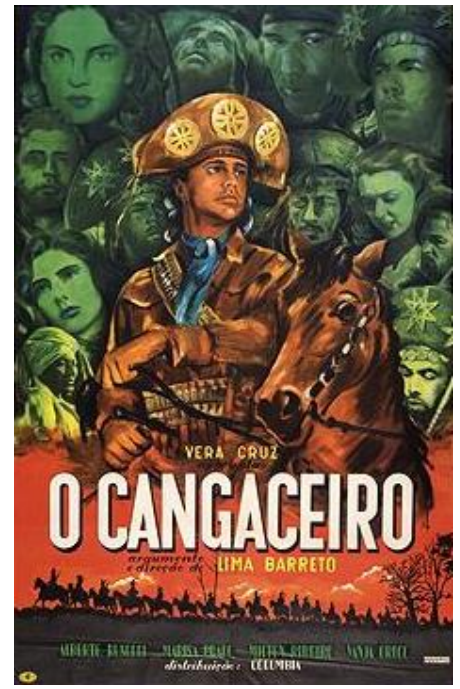

Fonte:<http://enciclopedia.itaucultural.org.br/obra67286/o-cangaceiro>.

Mas vejo como uma pista para entendermos o caminhar de nossa sétima arte, pois o gênero western, ainda levando em consideração os estudos de NEVES (2011), "remete à ideia de desbravamento, da tomada de um espaço no qual o selvagem cai e uma ordem não menos selvagem se instala" (p. 4). Ou seja, um campo fértil para o desenvolvimento de uma estética de violência, onde quando não é o "selvagem" que é tomado de fúria, o colonizador (ou o conquistador), 


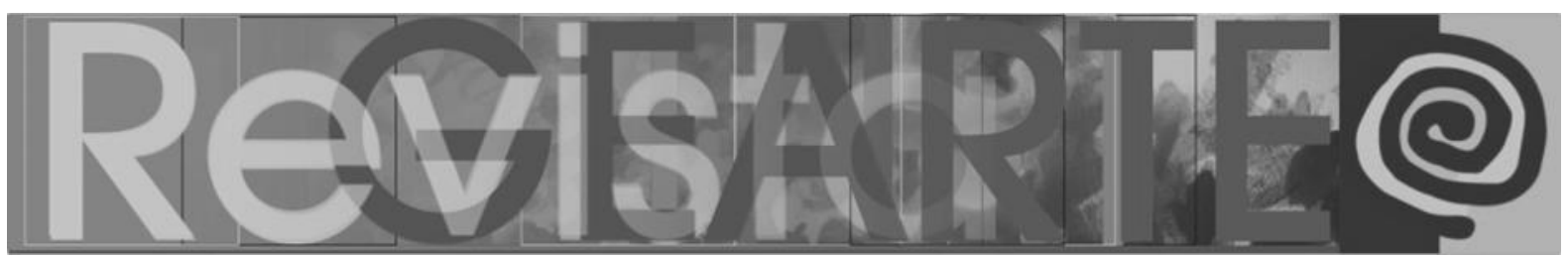

assume atitudes extremas de selvageria, como vemos no filme $O$ dragão da maldade contra o santo guerreiro (1969).

Vale analisarmos a quem a violência recai com maior perdurar, os corpos que sofrem violências constantes e os corpos que buscam desesperadamente não serem os próximos a sofrerem as mazelas. Grande incômodo, esperado, esse filme particularmente me traz, primeiramente pelo fato de perceber que apesar de não haver nenhum personagem negrx como principal, as maiores formas de violência e humilhação recaem sobre a população negra, sem que recebam nenhum tipo de pessoalidade.

Figura 4 - Montagem 01: Frames do filme O Dragão da Maldade Contra o Santo Guerreiro, de 1969

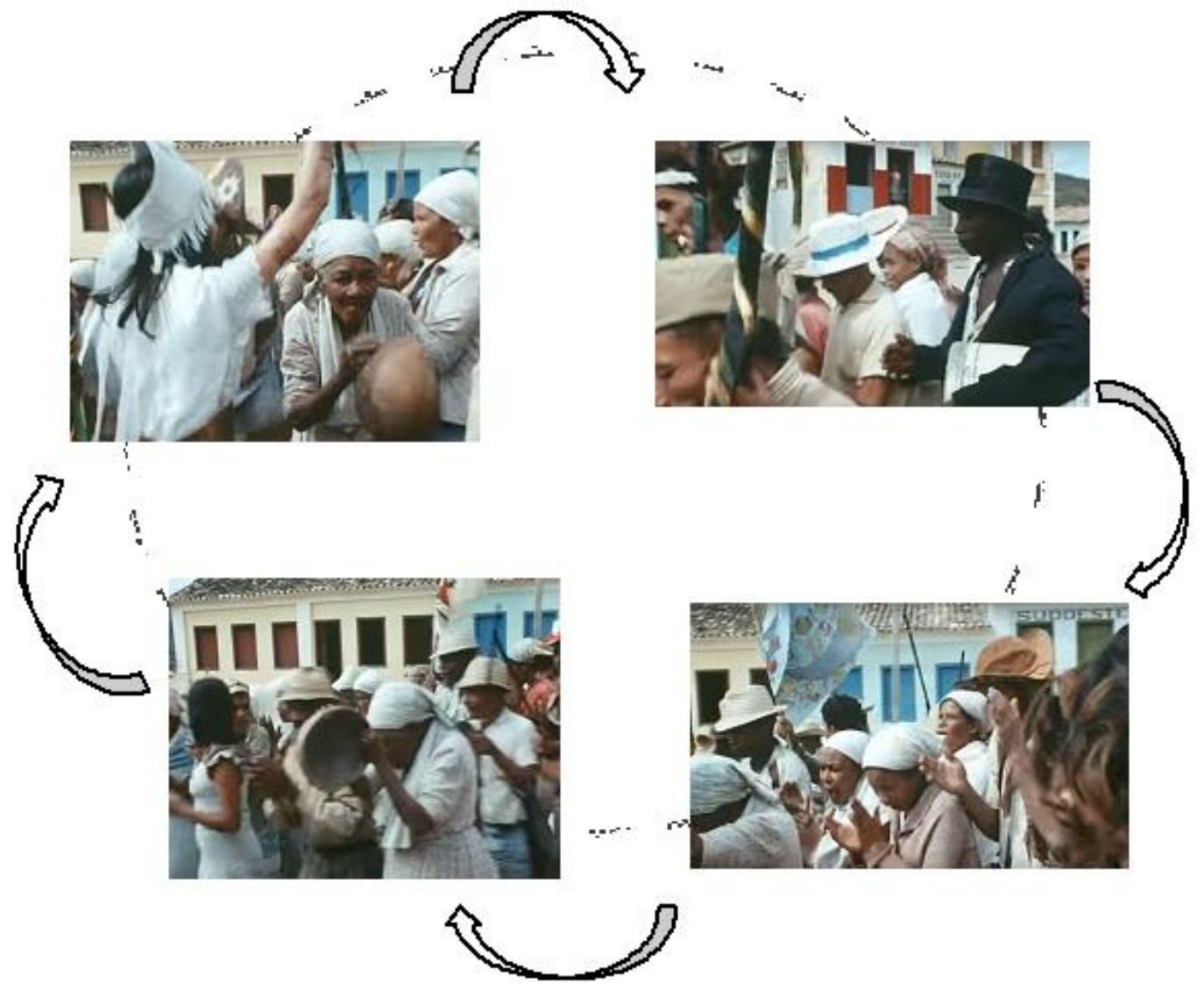

Fonte: Print pessoal feito a partir dos 22'17" do filme O Dragão da Maldade Contra o Santo Guerreiro.

Pelo contrário, são unificados como um único corpo, o povo brasileiro, uma verdadeira massa de manobra nas mãos da Santa, representada por uma mulher 


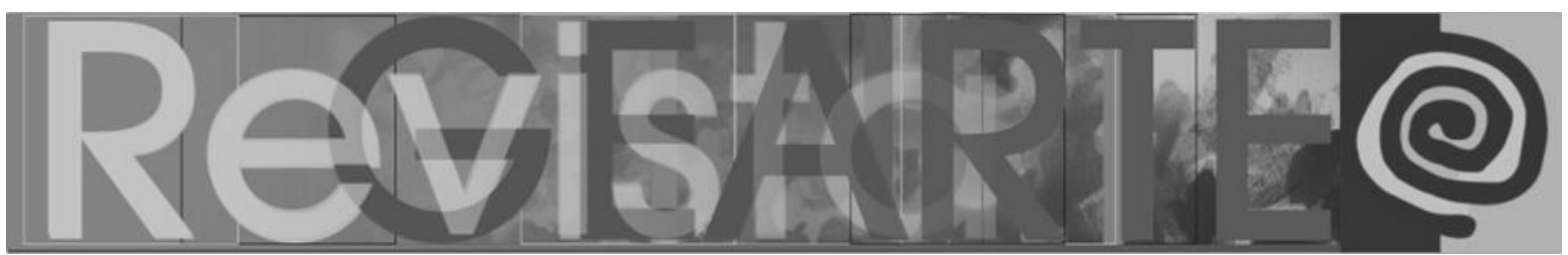

branca. Inclusive único biotipo de mulher que possui personagens, restando à mulher negra ser diluída em meio à massa humana que acompanha a Santa e o Cangaceiro, curiosamente também representado por um homem branco.

Figura 5 - Cabeças cortadas, armas e objetos pessoais de Lampião, Maria Bonita e mais nove cangaceiros, mortos no combate de Angico - Piranhas: AL

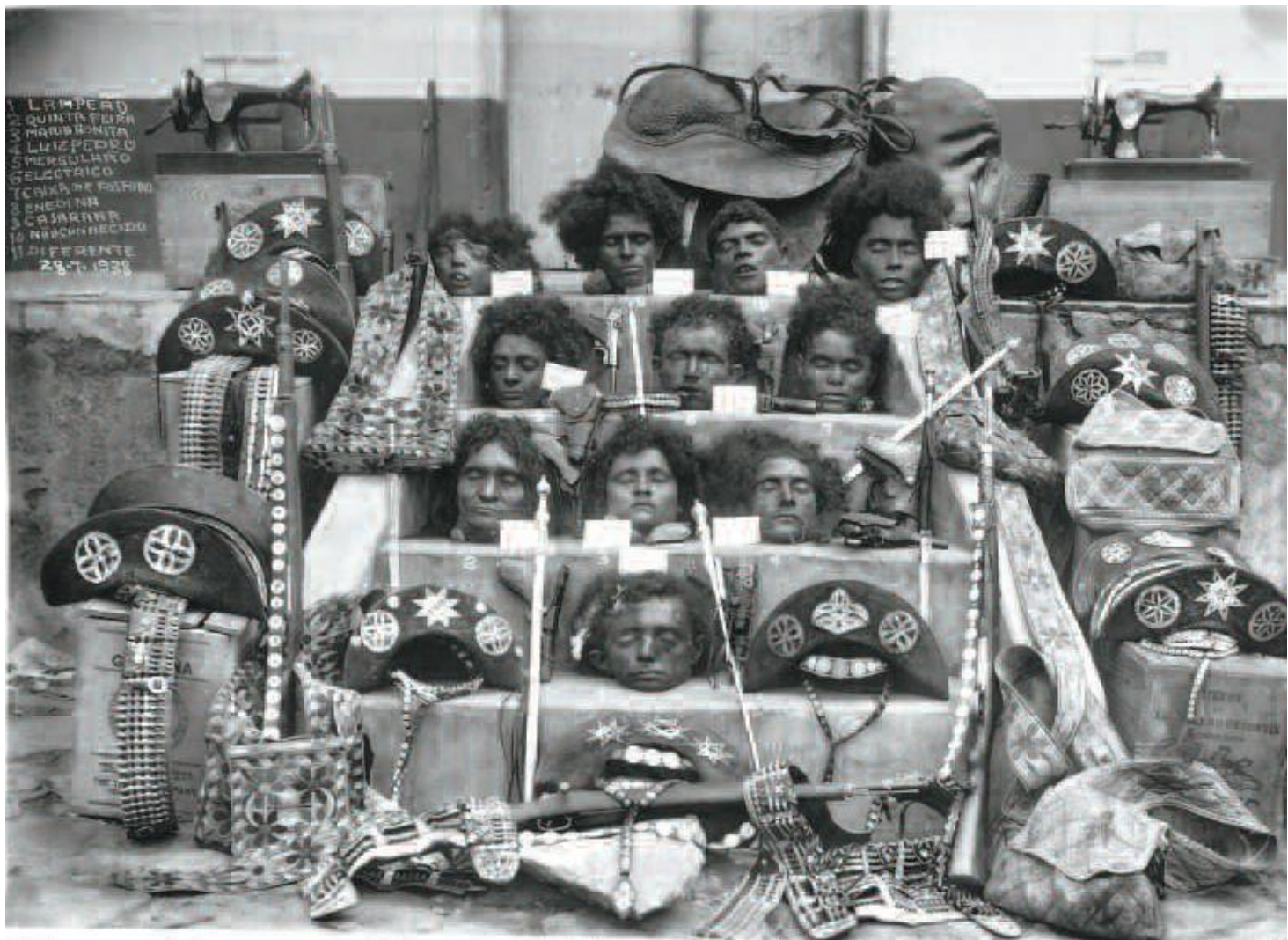

Fonte: Acervo Sociedade do Cangaço, Aracaju. Imagem retirada do texto Cangaço e Cangaçeiros: Histórias e Imagens Fotográficas do tempo de Lampião. Marcos Edílson de Araújo Clemente.

A violência reivindicada por Glauber Rocha em seu manifesto e também por suas produções enquanto uma estética da resistência de quem sente fome, se tornou uma faca de dois gumes para a comunidade negra. Pois ao mesmo tempo em que denuncia a barbárie que a população brasileira fica sujeita, em questões 


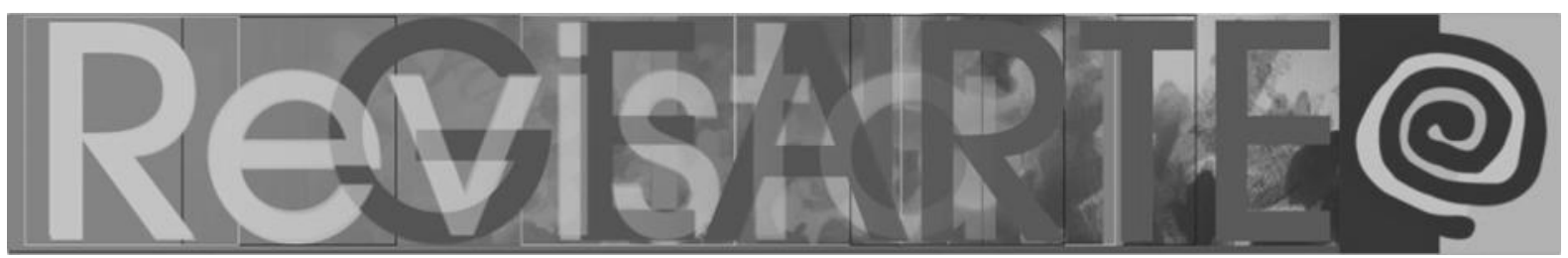

econômicas e políticas, também contribui para a normatização da violência em corpxs negrxs ${ }^{6}$ e suas formas estereotipadas construídas na subjetividade popular.

Tendo em vista que ao utilizar as mesmas estéticas difundidas pelo imperialismo industrial crescente na época, e foco neste artigo o gênero western, os filmes do Cinema Novo aqui citados, por fim, ainda reproduzem práticas de dominação como o racismo, sem de fato, combatê-lo. E como disse a filósofa ativista Angela Davis, em 1979, em um discurso em Oakland: "Numa sociedade racista, não adianta não ser racista, nós devemos ser antirracistas". ${ }^{7}$

Volto a refletir sobre a matéria publicada na EBC, citada no começo desse artigo, e, ainda querendo saber onde estão as mulheres negras na história da cinegrafia brasileira, continuo a olhar para a história atentamente. E mesmo o Cinema Novo sendo um espaço de contradições, ainda assim foi a chave que abriu as portas que deram espaços para pessoas negras no cinema brasileiro.

O principal nome que se é lembrado pela historiografia negra do nosso cinema é Zózimo Bulbul ${ }^{8}$, ator negro brasileiro, que, buscando construir narrativas outras a corpxs negrxs no cinema, também se tornou cineasta. Outra percursora que também terá seu berço no Cinema Novo é Adélia Sampaio, a primeira mulher negra a fazer um longa-metragem, em 1984, chamado Amor Maldito.

6 Neste artigo foco na questão dx corpxs negrxs, mas essa observação se estende a corpos não brancos em geral, e mulheres ainda muito presas na dualidade santa e puta que podemos observar no filme O Dragão da Maldade e o Guerreiro Justiceiro, de Glauber Rocha.

7 @ 2019 | Todos os direitos deste material são reservados ao NEXO JORNAL LTDA., conforme a Lei $n^{\circ}$ 9.610/98. A sua publicação, redistribuição, transmissão e reescrita sem autorização prévia é proibida.

8 Zózimo Bulbul atuou em vários filmes do Cinema Novo e foi primeiro ator negro a protagonizar uma novela na televisão brasileira - Vidas em conflito (1969), na TV Excelsior, sendo o percursor do Cinema Negro brasileiro com o curta Alma no Olho, 1973. Criou o Centro Afro Carioca de Cinema, responsável por evento que promove a aproximação entre cineastas brasileiros, africanos e caribenhos. 


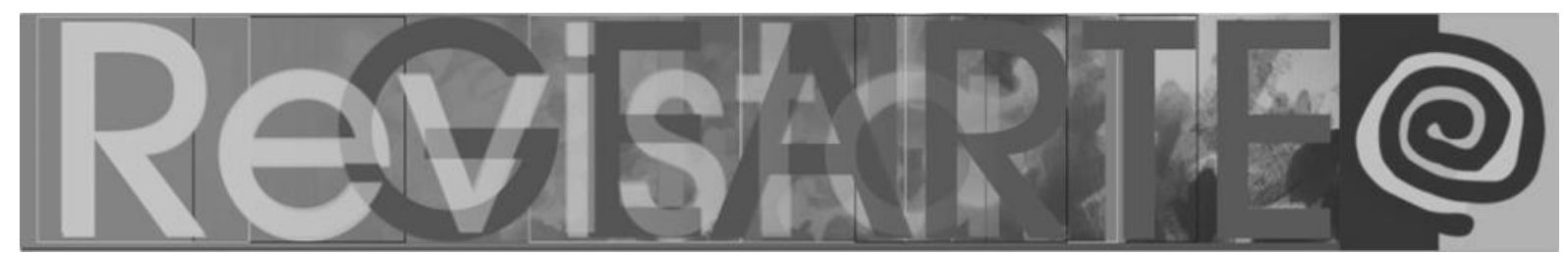

Figura 6 - Cartaz do filme 04: Amor Maldito, de Adélia Sampaio (1984)

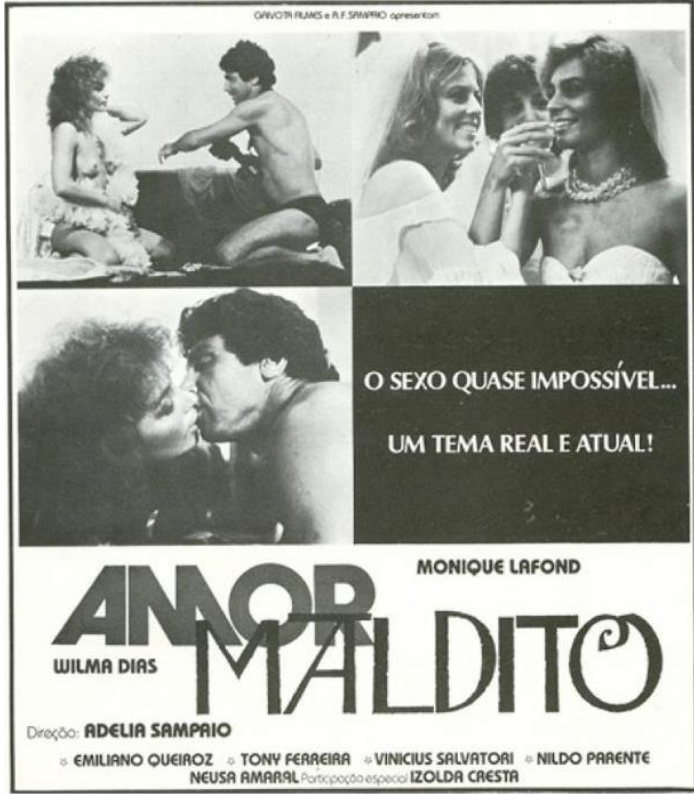

Fonte: http://www.verberenas.com/article/por-que-amor-malditoe-importante-para-nos-cineastas-negras-cheias-de-sonhos/.

Foco especial para a cineasta, filha de doméstica, que teve seu primeiro contato com o mundo do cinema sendo telefonista de uma produtora criada por cineastas do Cinema Novo. Foi nesse ambiente que nossa visionária alcançou a possibilidade de dirigir e comercializar um longa-metragem, o que é um ponto alto de reflexão nesse texto.

Ao contrário dos seus companheiros cinemanovistas, Adélia Sampaio teve total recusa por parte da Embrafilme na tentativa de financiar sua produção por se tratar da relação afetiva entre duas mulheres e expor a homofobia social, política e jurídica da época. Para poder realizar o filme, Adélia teceu conexão com várixs atores e técnicxs que a baixo custo produziram esse filme polêmico de forma colaborativa.

A exibição do filme também foi vetada por várias distribuidoras e salas de cinema por conta do teor do tema, sobrando como única possibilidade para a cineasta, após conversar com toda a equipe, enquadrar o filme no gênero pornográfico. 


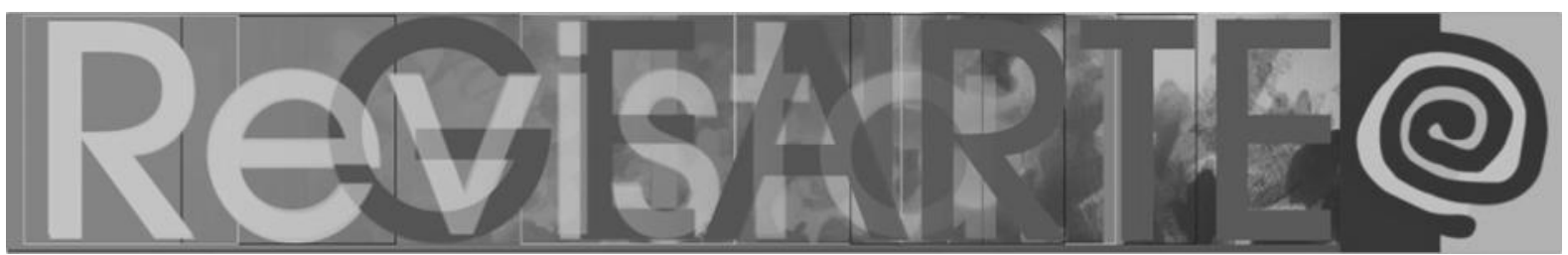

Após o fechamento da Embrafilme durante o governo Collor (1990-1992) ${ }^{9}$, as possibilidades de investimento e comercialização de filmes independentes se tornaram quase inexistentes para as mulheres negras, que por sua vez já tinham dificuldade em alcançar esses investimentos antes do fechamento da empresa. Assim, após esse período, se tornou quase impossível encontrá-las na história do cinema brasileiro.

Com relação à investigação sobre as matérias da Agência Brasil, encontro a entrevista ${ }^{10}$ da historiadora e coordenadora do Fórum Itinerante de Cinema Negro (Ficine), Janaína de Oliveira, explicando que o Cinema Negro "é um campo político, de luta por representação, de desconstrução de estereótipos" (2015). Janaína ainda pontua que além do samba, carnaval e futebol, hoje ainda temos o estereótipo da violência, como no caso do filme Cidade de Deus (Fernando Meirelles e Kátia Lund, de 2002), e aponta o desafio de se fazer imagens contra-hegemônicas.

Figura 7 - Cartaz do filme 05: Cidade de Deus, de Fernando Meirelles e Kátia Lund (2002)

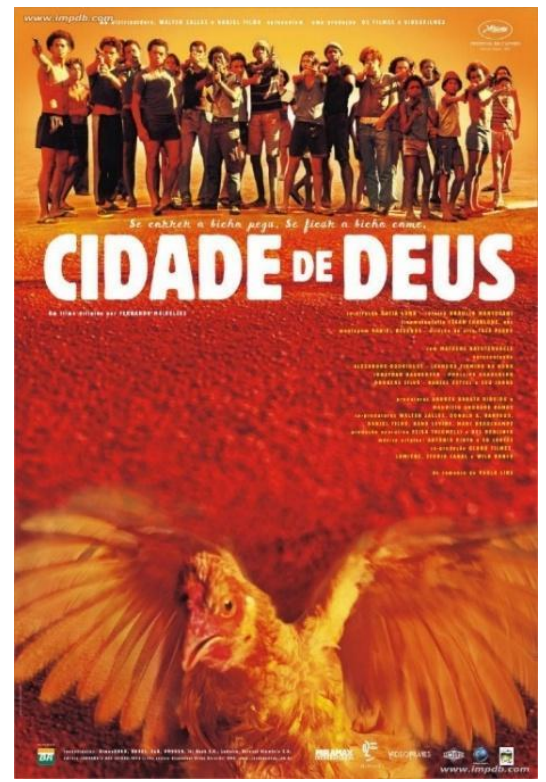

Fonte: https://pt.wikipedia.org/wiki/Cidade_de_Deus_(filme).

9 O principal referencial de pesquisa é o livro Economia da arte e cultura, idealizado pelo Centro de Documentação e Referência Itaú Cultural.

10 Repórter responsável: Isabela Vieira. 


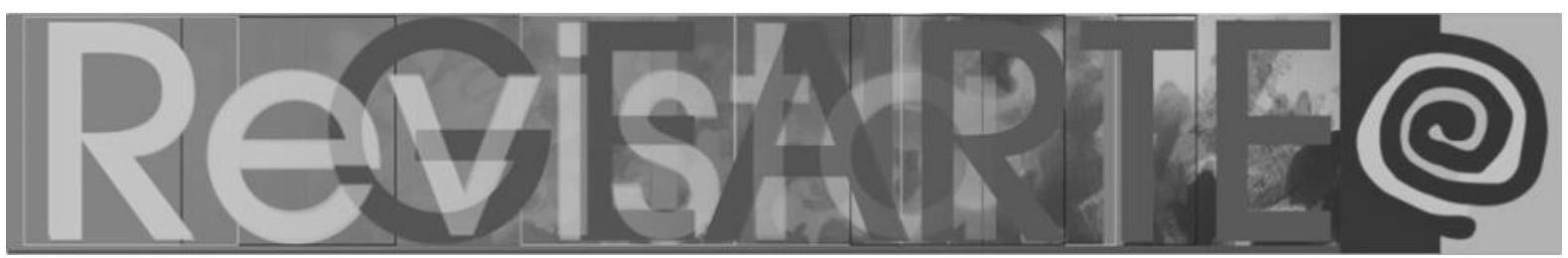

A manchete dessa matéria produzida pela repórter Isabela Vieira destaca que "O Cinema Negro no Brasil é protagonizado por mulheres", mas no decorrer da reportagem a coordenadora do Ficine explica que as produções em questão ainda se tratam de curtas-metragens. Isso acontece devido à dificuldade de pessoas negras em geral conseguirem acessar recursos para longas-metragens, talvez por isso mulheres negras não tenham sido encontradas na pesquisa de Marcia Rangel, que focou apenas em longas-metragens que alcançaram bilheteria.

Janaína Oliveira encerra a entrevista explicando a importância das redes de distribuição da produção, e mais do que apenas exibi-las, também debatê-las, pois ainda "vivemos em um contexto de imagens que precisamos desconstruí-las" (2015).

Criar espaços de exibição se torna uma alternativa importante para o cinema independente, ainda mais para produtores negrxs, que dependem de uma curadoria comprometida em quebrar o padrão de cinema hollywoodiano, como no caso retratado em uma matéria de 2017 da Agência Brasil, que fala sobre a Mostra de Diretoras Negras no Cinema Brasileiro, realizada pela Caixa Cultural em Brasília.

A Mostra alcançou ao todo 45 filmes, entre longas, médias e curtasmetragens, fazendo uma retrospectiva pelas produções das cineastas negras brasileiras, e é nessa matéria que encontro pistas importantes de onde estariam nossas cineastas. A partir do link ${ }^{11}$ da programação apresentada no evento da Caixa Cultural, o curta Gurufim na Mangueira, produzido por Ana Dandara em 2000, é o filme mais antigo depois do de Adélia Sampaio, produção realizada 16 anos após o trabalho de nossa visionária.

Nossa história possui um abismo de 16 anos, no qual se supõe que não há produtoras negras. A pesquisa para encontrar mais pistas de onde estamos nesse

11 <http://www.caixacultural.gov.br/SitePages/evento-detalhe.aspx?uid=1\&eid=1487> 


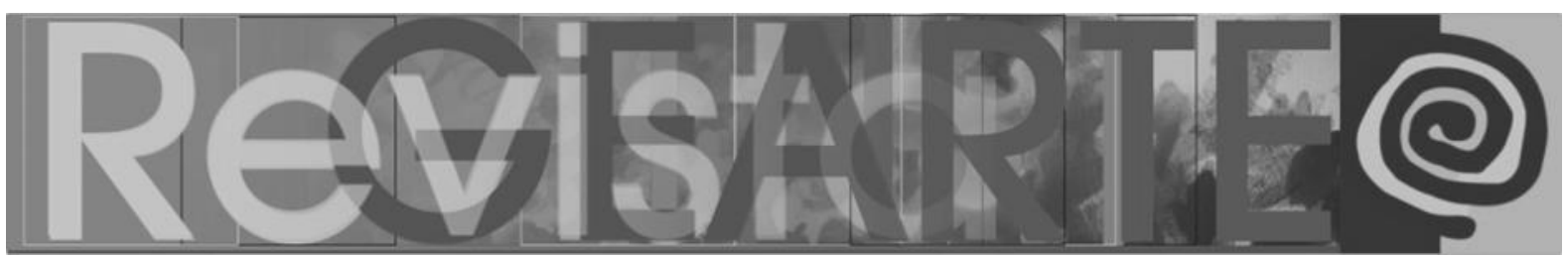

pedaço da história continua, mas ainda tenho dificuldade para enxergá-las, devido à claridade hegemônica ainda muito presente no cinema.

Como Janaína expõe na entrevista concedida à Agência Brasil, as mulheres negras vêm ganhando destaque nos últimos anos por se colocarem na linha de frente na desconstrução desses padrões cinematográficos. E mais do que apenas produtoras dos filmes, as mulheres do audiovisual, que em geral tem pouca visibilidade, vêm se organizando e criando espaços para se verem e também possibilitarem que seus trabalhos sejam vistos, antes mesmo de investimentos como o da Caixa Cultural. É o caso do Festival Internacional de Cinema de Realizadoras (Fincar), que teve sua primeira edição em Recife em 2016 e contou com 30 filmes de 19 países.

Dentre sua curadoria estava a historiadora Janaína Oliveira, que por trabalhar a alguns anos em parceria com a Fespaco (O Festival Panafricano de Cinema e Televisão de Ouagadougou, maior festival de cinema da África), esteve à frente da curadoria dos filmes africanos do evento e conduziu uma roda de diálogo sobre o Cinema Negro no feminino.

A curadora negra explica que historicamente a mulher negra é "representada de forma negativa - como unicamente um corpo, um objeto com atributos negativos, que corrompe, que seduz. "O que quero ressaltar com esse artigo é que o desafio com o qual as cineastas negras vêm lidando para quebrar a vigência dos estereótipos atribuídos não se restringe apenas à produção, mas também à distribuição de seus trabalhos, fator que influencia sua visibilidade ou invisibilidade.

Esse fator de visibilidade/ invisibilidade é enfrentado pelas mulheres negras em diversos segmentos além do cinema, um deles também é o meio acadêmico. 


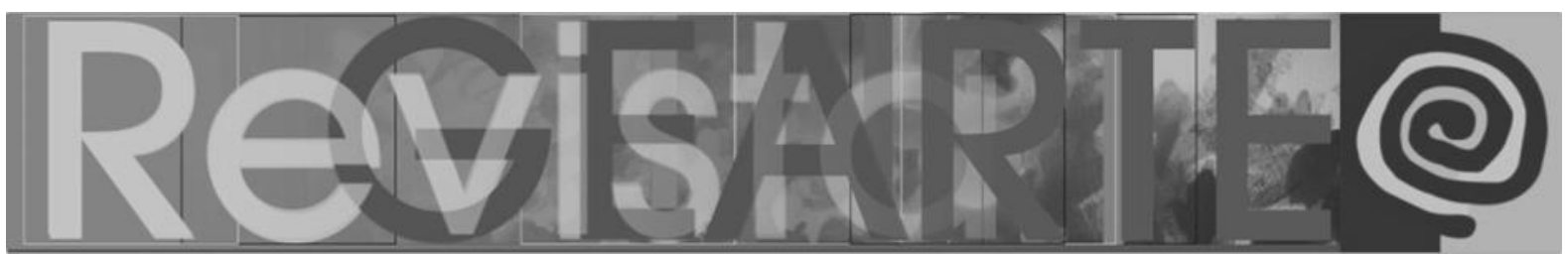

Esse método de apagamento de um olhar ${ }^{12}$ e/ou pensamento ${ }^{13}$, se dá pela legitimação da hierarquia do pensamento, sobre essa forma de dominação, bell hooks (2017) nos ensina ${ }^{14}$ :

Claramente, um dos usos que esses indivíduos fazem da teoria é instrumental. Usam-na para criar hierarquias de pensamento desnecessárias e correntes que endossam as políticas de dominação na medida em que designam certas obras como inferiores ou superiores, mais dignas de atenção ou menos. (HOOKS, 2017, p. 89).

Cineastas negras buscam formas de driblar essa hierarquia, e uma dessas formas é não permitir que a caminhada iniciada por Adélia Sampaio seja apagada. Suas produções e história foram seguidas por outras mulheres como produtoras, roteiristas, diretoras e cinegrafistas. Mas infelizmente a história insiste em não mostrá-las, como se elas tivessem menos valia na construção do cinema.

Mesmo que Adélia tenha destoado do que atualmente é chamado de estética do cinema negro por não comportar pessoas negrxs entre o núcleo de protagonistas, parafraseando a pesquisadora Evelyn Sacramento (2017), Adélia é uma cineasta que ousou ser e a sua obra carrega o legado da resistência por insistir em fazer seu filme rodar, subvertendo as camadas.

\begin{abstract}
Adélia inova em sua narrativa ao trazer para as telas um romance lésbico, ela traz o olhar feminino sobre a lesbianidade, suas subjetividades e nuances, principalmente por ser um período em que questões como estas, eram pouco ou nada abordadas pela mídia e principalmente, pela perspectiva feminina, através de uma narrativa que não fosse erotizante ou animalesca, isso, levando em consideração que ainda hoje é um grande tabu para a mídia. (SACRAMENTO, 2017, p. 5).
\end{abstract}

Mulheres Negras dentro do cinema BR se alimentam constantemente do aprendizado trazido pelxs nossxs dois "abre alas" da história de cineastas negrxs

12 Me refiro aqui às produções audiovisuais, que retratam sobretudo a forma que os produtores enxergam o tema que apresentam.

13 Me refiro, a forma de constituição intelectual, do desenvolvimento de alguma teoria.

14 Uso esse termo, para fazer uma menção implícita do trabalho dela que apresento como referência, Ensinando a Transgredir, escrito pela primeira vez em 1994, nos Estados Unidos e que no Brasil já está em sua quarta triagem. 


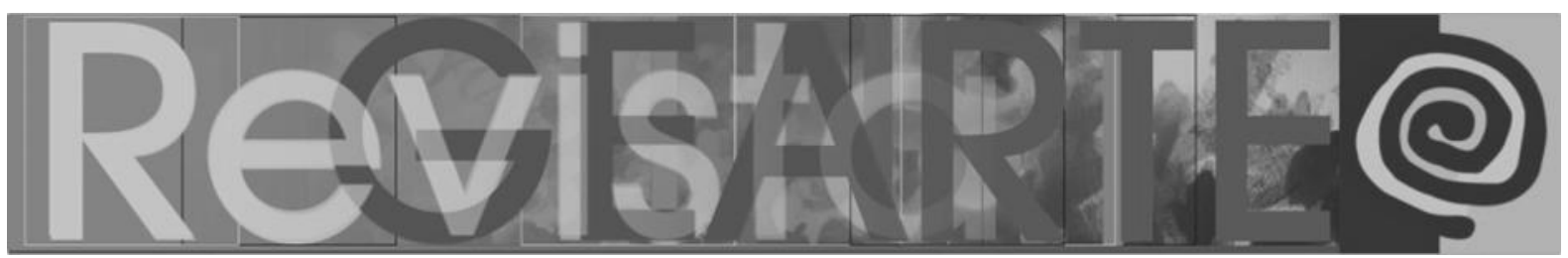

brasileirxs. E da construção estética de Zózimo e a audácia (transgressão) de Adélia começam a imergir, a partir de 2015, produções que que não são passíveis de invisibilização, como o filme Kbela.

Através do contato com o trabalho da professora negra americana bell hooks, em particular com sua obra Ensinando a Transgredir, publicada pela primeira vez em 1994, pude identificar dois conceitos que considero importantes e podem ser pistas viáveis para começarmos uma mudança de olhar para a história do cinema brasileiro, tanto dentro da comunidade como dentro da academia.

O primeiro é a autoatualização, necessária para que pesquisadores em geral não continuem reproduzindo a mesma lógica, de contar uma "única história"15 e hierarquia de pensamento. Para isso, é necessário que comecem um trabalho interno constante de perceberem que existem outras histórias a serem contadas dentro da história do cinema.

Algumas vezes, como no caso da pesquisa de Marcia Rangel, que olha apenas longas-metragens em um determinado período, e, que se não houver cuidado ao passar as informações deixa escapar o fato que, apesar de não haver cineastas negras no circuito comercial entre 2002 a 2012, ainda assim elas existem. Se já tivéssemos avançado nessa discussão, poderíamos começar a nos questionar diretamente sobre o porquê de elas não terem recebido investimento para seus longas durante esse período.

Ao invisibilizar as mulheres negras, também é apagado um lugar de fala do Cinema Negro, que justamente é comprometido em quebrar estereótipos. O que infelizmente movimentos de resistência dentro do cinema nacional, como o Cinema Novo, não deram conta de debater. Contribuindo ainda para a atribuição de uma

15 "O perigo da história única" é o título de uma palestra ministrada pela escritora nigeriana Chimamanda Adichie, em que explica o erro de se sobressair apenas um ponto de vista acerca de uma história, principalmente quando se trata da história de um povo. 


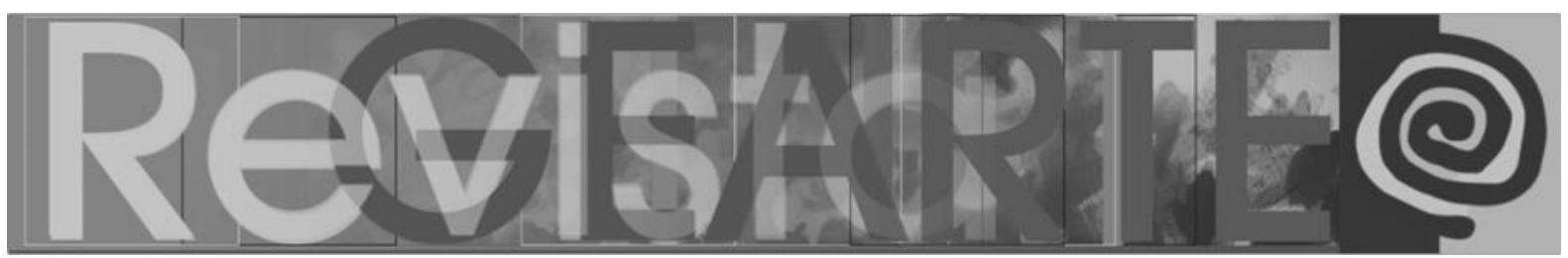

estética da violência, associada ao corpx negrx, que perdura até hoje em produções no Cinema Brasileiro.

E é nesse compromisso do Cinema Negro que vejo o segundo conceito de bell hooks. Ao buscar quebrar estereótipos, temos a necessidade de transgredir, assim como Adélia Sampaio fez, em 1984, para transpor as limitações que o conservadorismo da época impunha. Coloco aqui a palavra transgredir, entendida como ação humana que atravessa, ultrapassa noções que pressupõem a existência de uma norma que estabelece e demarca limites. E, segundo a autora, estimular o entusiasmo é um ingrediente importante no ato de transgredir dentro do campo educacional, e amplio também para o campo artístico.

Como disse Janaína de Oliveira em 2016, em uma entrevista para Diálogos Ausentes, "o Cinema Negro é um projeto em construção no Brasil", e certamente a mulher negra é uma base firme que não permite que essa construção se desmorone. Exemplos arrastam e entusiasmam novas produções, como as que foram exibidas no Encontro de Cinema Negro Zózimo Bulbul, maior festival de Cinema Negro da América Latina, que alcançou sua 11aㅡ edição, produzida em 2019 por Janaína de Oliveira e Viviane Ferreira, sendo essa última outra cineasta brasileira importante em nossa história, que ainda segue sendo escrita.

\section{Referências}

BOLAÑO, César; GOLIN, Cida; BRITTOS, Valério. (Orgs.). Economia da arte e da cultura. Centro de Documentação e Referência Itaú Cultural. São Paulo: Itaú Cultural; São Leopoldo: Cepos/Unisinos; Porto Alegre: PPGCOM/UFRGS; São Cristóvão: Obscom/UFS, 2010.

CLEMENTE, Marcos Edílson de Araújo. Cangaço e cangaceiros: histórias e imagens fotográficas do tempo de Lampião. Fênix - Revista de História e Estudos Culturais, São Paulo, v. 4, n. 4, p. 1 18, out./dez. 2007.

DEUS e o Diabo na Terra do Sol. In: ENCICLOPÉDIA Itaú Cultural de Arte e Cultura Brasileiras. São Paulo: Itaú Cultural, 2020. Disponível em: <http://enciclopedia.itaucultural.org.br /obra70172/deus-e-o-diabo-na-terra-do-sol>. Acesso em: 07 de jun. 2020. Verbete da Enciclopédia. ISBN: 978-85-7979-060-7

GATTI, André Piero. Embrafilme e o cinema brasileiro [recurso eletrônico]. São Paulo: Centro Cultural São Paulo, 2007. Disponível em: <https://www.academia.edu/420392/Cole\% C3\%A7\%C3\%A3o_Cadernos_De_Pesquisa > Acesso em: 07 de jun. 2020. 


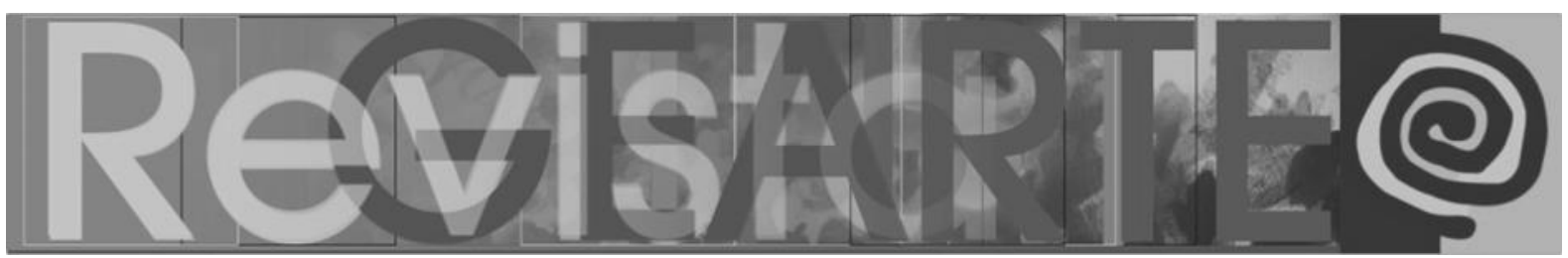

HOOKS, bell. Ensinando a transgredir: a educação como prática da liberdade. Tradução de Marcelo Brandão Cipolla. 2를 ed. - São Paulo: WMF Martins Fontes, 2017.

NEVES, Anderson Rodrigues. Entre o western e o nordestern: os possíveis diálogos entre Lima Barreto e Glauber Rocha no cinema de cangaço (O Cangaceiro - 1953 e Deus e o Diabo na Terra do Sol - 1964). In: XXVI Simpósio Nacional de História - ANPUH, 2011, São Paulo. Anais [XXVI Simpósio Nacional de História - ANPUH]. São Paulo, p. 1-9.

O Cangaceiro. In: ENCICLOPÉDIA Itaú Cultural de Arte e Cultura Brasileiras. São Paulo: Itaú Cultural, 2020. Disponível em: <http://enciclopedia.itaucultural.org.br/obra67286/o-cangaceiro>. Acesso em: 07 de jun. 2020. Verbete da Enciclopédia. ISBN:978-85-7979-060-7

OLIVEIRA, Janaína. Diálogos Ausentes. In: Itaú Cultural. São Paulo: Itaú Cultural, 2016. Disponível em: <https://www.itaucultural.org.br/janaina-oliveira-dialogos-ausentes-2016> Acesso em: 25 jun. 2018.

PEREIRA, Miguel. O Columbianum e o cinema brasileiro. ALCEU, v. 8, n.15, p. 127-142, jul./dez. 2007.

ROCHA, Glauber. Uma estética da fome. Revista Civilização Brasileira, n. 3, p. 165-170, jul.1965.

SACRAMENTO, Evelyn dos Santos. Adélia Sampaio: uma cineasta que ousou ser. In: Seminário Internacional Fazendo Gênero 11 \& 13 th Women's Worlds Congress, 2017, Florianópolis. Anais Eletrônicos. Florianópolis, p. 1-10. ISSN 2179-510X. Disponível em: <http://www.en. wwc2017.eventos.dype.com.br/resources/anais/1503004228_ARQUIVO_EvelynSacramentoAdeliaSampaio.pdf> Acesso em: 20 jun. 2019.

SAMPAIO, Adélia. Cineasta fala sobre Amor Bandido. Portal Infonet. Entrevista concedida Kátia Susanna. Aracaju, 24 de fevereiro de 2016. Disponível em: <https://www.youtu be.com/watch?v=BSlu-PRHPhs> Acesso em: 20 jun. 2018.

SIEGA, Paula. A estética da fome: Glauber Rocha e a abertura de novos horizontes. CONFLUENZE, Dipartimento di Lingue e Letterature Straniere Moderne, Università di Bologna, v. 1, n. 1, p. 158-177, 2009.

VERDÉLIO, Andreia. Caixa Cultural abre mostra de filmes de diretoras negras em Brasília. Agência Brasil- Empresa Brasileira de Comunicação (EBC). Brasília, 04 de setembro de 2017. Seção Geral. Disponível em:<http://agenciabrasil.ebc.com.br/cultura/noticia/2017-07/caixa-cultural-abre-mostrade-filmes-de-diretoras-negras-em-brasilia > Acesso em: 31 ago. 2019.

VIEIRA, Isabela. Pesquisa revela que mulheres negras estão fora do cinema nacional: pesquisa mostra que apesar de ser a maior parte da população feminina. Agência Brasil - Empresa Brasileira de Comunicação (EBC). Rio de Janeiro, 06 de julho de 2014. Seção Geral. Disponível em: $<$ http://agenciabrasil.ebc.com.br/cultura/noticia/2014-07/pesquisa-revela-que-mulheres-negrasestao-fora-do-cinema-nacional> Acesso em: 31 ago. 2019.

VIEIRA, Isabela. Cinema negro no Brasil é protagonizado por mulheres, diz pesquisadora. Agência Brasil - Empresa Brasileira de Comunicação (EBC). Rio de Janeiro, 26 de dezembro de 2015. Seção Geral. Disponível em: <http://agenciabrasil.ebc.com.br/cultura/noticia/2015-12/cinemanegro-no-brasil-e-protagonizado-por-mulheres-diz-pesquisadora> Acesso em: 31 ago. 2019.

\section{Bárbara Cezano Rody}

Possui graduação em Licenciatura pelo curso de Artes Visuais da Universidade Federal de Pelotas (UFPel), atuando em projeto de pesquisa em torno da fotografia, voltado para estudos sobre vivências cotidianas e seus imaginários em diferentes contextos, junto ao Núcleo de Pesquisa Photographein e desenvolvendo de forma autônoma a ideia do professor-artista pensando performance como um ato educativo. Participou da fundação do Centro Cultural Marrabenta, Pelotas-Maputo, ajudando na produção de eventos culturais, com o fim de promover a cultura negra

RODY, Bárbara Cezano; CHAVES, Larissa Patron. Uma estética da violência presente 370

no cinema brasileiro e o apagamento de mulheres negras nas produções audiovisuais.

Revista GEARTE, Porto Alegre, v. 7, n. 2, p. 353-371, maio/ago. 2020.

Disponível em: http://seer.ufrgs.br/gearte 


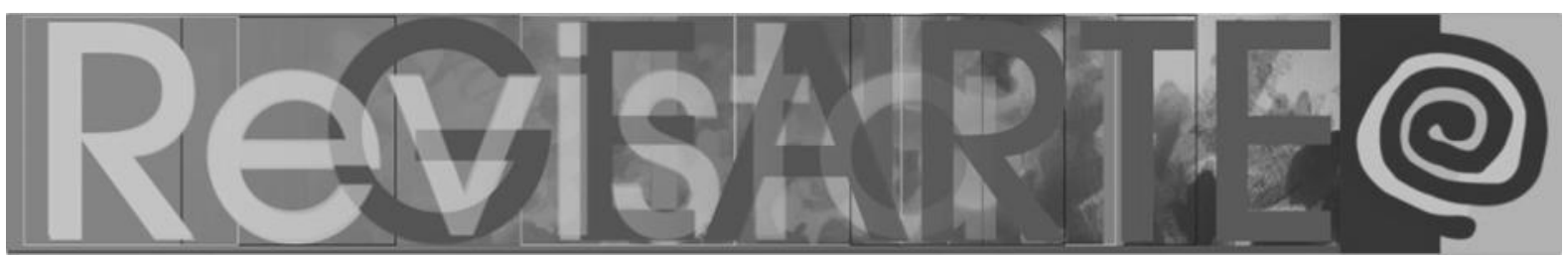

local e de Maputo (Moçambique) e contribuir com produções digitais. As vivências nesse espaço levaram a criar o The Black Cine, Mostra de Cinema Negro. Atualmente é mestranda do Programa de Pós-Graduação em Artes Visuais pela UFPel, na Linha de Pesquisa: Educação em Artes e Processos de Formação Estética Área: Audiovisual, bolsista do programa DS/CAPES e integrante do grupo de pesquisa de Caixa de Pandora.

Orcid: https://orcid.org/0000-0003-4006-700X

E-mail: barbarac.rody@gmail.com

Currículo: http://lattes.cnpq.br/5206612386075236

\section{Larissa Patron Chaves}

Professora Associada do Centro de Artes da Universidade Federal de Pelotas. Possui Graduação em Artes Visuais pela Universidade Federal de Pelotas, Mestrado em História pela Pontifícia Universidade Católica do Rio Grande do Sul, Doutorado em História pela Universidade do Vale do Rio dos Sinos, com período de atuação em estágio de doutoramento na Universidade do Porto (Portugal) e Pós Doutorado em História, pelo Centro de Investigação em Ciência Política da Universidade de Évora, Portugal. Possui trabalhos desenvolvidos na área de mobilidade acadêmica na UFPel, orientando estágios de graduação através de convênios com universidades latino americanas, portuguesas e espanholas. Coordena o grupo multidisciplinar de pesquisa "Imaginária Sacra no Rio Grande do Sul" colaborando com a comunidade paroquial de Pelotas e museus locais no levantamento, catalogação e salvaguarda do patrimônio sacro da cidade e região. Atualmente integra o corpo docente permanente do Mestrado em Artes Visuais e o corpo docente permanente do Mestrado e Doutorado em História, ambos da Universidade Federal de Pelotas.

Orcid: https://orcid.org/0000-0003-1678-7007

E-mail: larissapatron@gmail.com

Currículo: http://lattes.cnpq.br/3858201697400054

Recebido em 29 de fevereiro de 2020 Aceito em 17 de maio de 2020 